\title{
SEDIMENT TRANSPORT FIELDS AROUND OFF-SHORE AND ON-SHORE STRUCTURES
}

\author{
Mohamed Abdelnaser Elsayed Mortada \\ Department of Engineering Mathematics and Physics, Faculty of \\ Engineering, Fayoum University. \\ E-mail:mae05@fayoum.edu.eg \\ Professor Dr. Mohamed Eissa Sayed Ahmed \\ Professor of Engineering Mechanics, Department of Engineering \\ Mathematics and Physics, \\ Faculty of Engineering \\ Fayoum University \\ E-mail: mes00@fayoum.edu.eg \\ Dr. Mohamed Ahmed Morad \\ Department of Civil Engineering- Faculty of Engineering \\ Fayoum University \\ Dr. Ahmed Mohamed Abdeltawab Alkaisy \\ Department of Engineering Mathematics and Physics, Faculty of \\ Engineering, Fayoum University. \\ E-mail: ama02@fayoum.edu.eg
}

\begin{abstract}
A two-dimensional numerical sediment transport model in the field of off-and on-shore was developed. Sediment defined as fractionated materials of rocks formed by various physical and/or chemical processes. The transport is caused by the effects of gravity and friction with the air or liquid containing that sediments. Hydrodynamical modeling simulates flow velocity which we can use it in the sediment transport model to simulate sediment concentration. This paper reports development of a two-dimensional depth-averaged advection-diffusion equation with source term to simulate the depth-averaged suspended sediment concentration to predict suspended and bed load transport and change of bed elevation. The source term represents the difference between the deposition of the bed surface and the entrainment of the suspended sediment. The fractional step method Sobey (1983), was used to separate this equation into the advection step and diffusion step. The advection step solved using a several finite difference schemes. Then used semi-implicit finite-difference to solve the diffusion step and transform it into linear system equations which solved numerically by a suitable numerical method.
\end{abstract}

Keywords: Sediment transport, Numerical modeling, 2D depth-averaged, Deposition. 


\section{Introduction}

Numerical modeling is the best way for analyzing any natural system to understand the process. The numerical simulation uses a variety of empirically derived formulations to build the solution. The validation of that numerical solution with the existing data is necessary to justify the accuracy of that solution. So, we considered the numerical simulation a very effective method to stimulate sediment transport. In numerical modeling of sediment transport, we considered a hydrodynamical and morphodynamical part. The hydrodynamical part deals with waves, wind, tides, and currents. Which wind generates the waves and the properties of that waves depend on the speed of winds and depth of water. The energy of the winds transforms to wave energy and propagate waves in several directions. Breaking waves in the close zone of shoreline or structures are controlling how the sediment is transported. So, the hydrodynamical part simulates flow velocity using many variables. The morphodynamical part represents the change in the bed elevation and fluid dynamics which includes sediment transport. It depends on hydrodynamics variables from the hydrodynamical part and simulation of sediment transport. In this paper, we're focusing on the morphodynamic part which is controlled by the sediment transport rate in the zone due to currents, waves, and sediments. The rate of sediment transport can be defined as the product of instantaneous velocity and the instantaneous sediment concentration. The profile of concentration can be developed from the advection-diffusion equation. The sediment transport is divided into suspended load and bed load. The fractional step method was used to solve the two-dimensional advection-diffusion equation which separates this equation into the advection step and diffusion step. Each step solved by suitable numerical method. Many researchers have developed various analytical and theoretical models based on experimental studies. These
Analytical methods also cannot be applied effectively to real world problems. The reasons for this are that these studies bring many simplifications and are the criteria of these studies tiny. However, we cannot neglect the importance of these analytical and physical studies. Because these tools can be used to validate today's popular complex models. With using the computers, a new era in sediment transport studies began. Computer models. First, the simplest analytical transport of sediments was modeled on a computer. These computer models have proven useful and efficient, such as using computers to model or to simulate. The simulation reduced the time and human energy required to perform the calculation. These computer model simulations and predictions were accurate. Then came the numerical models, which completely changed the world of simulations and modeling. In these numerical methods, we can represent a water system by partial differential equations representing the conservation of mass and the conservation of momentum. We used to solve these partial differential equations using the numerical methods. And it allowed us to solve complex partial differential equations that could not be solved with analytical methods. Numerical modeling implemented. Another advantage of this, we can simulate physical processes with greater precision than experimental and analytical methods. For these reasons, computer modeling is now widely used for all kinds of real-life problems. All the developed analytical mathematical models of sediment transport are based upon the assumption of either steady or quasi steady water flow. The unsteady state of the water flow is difficult to develop an analytical solution because it makes the system complex. In our life problems this assumption is generally not true. This assumption is generally not true for real life problems. To solve this problem the researchers solved sediment transport equations in complex situations by developing numerical methods. This method advances by using computers and requires enormous 
calculations. Until now, many numerical models of sediment transport have been developed in one or two-dimension.

In one-dimensional modeling of sediment transport, the average concentration is calculated in vertical directions. This is the simplest type of sediment transport modeling because the equations are used in only one direction. This approach is easy to implement because analytical solutions can be easily developed for one-dimensional differential equations, but this approach cannot be implemented if longitudinal or vertical flow is also important. Garde (1965) developed a onedimensional numerical model to simulate degradation under almost stable conditions state of flow conditions. Gesseler (1971) used a finite difference method to develop a oneDimensional model numerical model to predict degradation and aggradation. Analytical and numerical models of sediment transport have been developed. Jansen (1979), Cunge (1980), and De Vries (1989) have examined one-dimensional models. De Vries (1967) used an explicit finite difference scheme to develop a numerical model to calculate the height of the bed and the profile of the water surface during aggregation in the channel. This method was able to produce accurate results by imposition a limitation on the step of time. Cunge (1973) used this model and solved it implicitly using finite difference diagram to overcome the problem of limiting time phases. Swamee (1974) developed a numerical aggregation model against a constant flow dam. He used the iteration method and solved the equation for the value of the small-time step, then smoothed the final bed profile using the sinusoidal Fourier series. Mahmood (1975) developed a numerical model by taking into account the temporal and spatial changes of the suspended load. Used an implicit finite Difference diagram for the numerical solution of the model. Tomas and Prashum (1977) formulated the model of the hydraulic engineering center (HEC-6) in straight coordinates and described it using fine differentiation schemes. This model was introduced for the movement of sediments at constant speed in rivers with gravel bottoms. Then, Karim and Kennedy (1982) have developed the Iowa ALLUVIAL (IALLUVIAL) model based on rectilinear coordinate system and the Saint Venant flow equations in an almost constant flow. The obvious difference between the IALLUVIAL model and the HEC- 6 model there is that HEC-6 solves the differential conservation equation of energy instead of the equation of the moment. Some of the most widely used one-dimensional models are MIKE11 (DHI 2003) (A Modelling System for Rivers and Channels) for the erosion, transport and deposition of sediments in channels and straight rivers. In the two-dimensional model of sediment transport, the sediment concentration is direction averaged, generally vertical, depending on certain needs and flow characteristics. Based on this integration, twodimensional models can be deeply integrated and laterally integrated two-dimensional models. Applications of two-dimensional models are more complicated than onedimensional models because this approach requires more resources in all parts. Twodimensional models are more popular models than others. Struiksma (1985) developed a two-dimensional sediment transport model to simulate this Extensive bed change at Delft Hydraulics. Shimizu and Itakura (1989) developed a two-dimensional model of bedload transport in the bottom for alluvial channels. Some of the most important twodimensional sediment transport models are TABS-2 (Thomas and McAnally, 1990), HSCTM2D (Hayter, 1995), CCHE2D (Center for Computational Hydroscience and Engineering) (Wu W., 2001), and MIKE21 (DHI, 2003). CCHE2D sediment transport model is One of the most popular sediment transport models (Wu W, 2001) developed that at the National Center for Computational and Hydroscience Engineering, University of Mississippi. The CCHE2D model has an unsustainable sediment transport model for suspended load and an equilibrium sediment 
transport model for bedload. The CCHE2D model can take into account irregular sediment mixtures of many size classes. The exponential difference scheme is used in CCHE2D model to solve the equation of bedload transport. HSCTM2D (Hydrodynamic, Sediment and Contaminant Transport Model) model was developed for the US EPA (Environmental Protection Agency) and it is a vertically integrated twodimensional finite element model for cohesive sediments. HSCTM2D consists of two parts. First is the hydrodynamic modeling part called HYDRO2D, the other is the pollution and sediment Part of transport modeling known as CS2D. HSCTM2D can be used for both shortterm and long-term use simulation.

\section{Suspended load transport}

Floating sediments are relatively smaller, so they are picked up by the current and remain in suspension as they move. It does not respond immediately to wave conditions or flow. The orbital movements caused by waves are responsible for the excitation of the fine grains from the bed and made it floating which affect the concentration of the stream. We can obtain the concentration of suspended sediment transport from a depth-averaged advection-diffusion equation of conservation form as:

$$
\begin{array}{r}
\frac{\partial h C}{\partial t}+\frac{\partial U h C}{\partial x}+\frac{\partial V h C}{\partial y}=\frac{\partial}{\partial x}\left(k_{x} h \frac{\partial C}{\partial x}\right)+ \\
\text { (1) } \frac{\partial}{\partial y}\left(k_{y} h \frac{\partial C}{\partial y}\right)+E-D
\end{array}
$$

Where: $C$ is the depth averaged sediment concentration, $\mathrm{U}, \mathrm{V}$ are velocities of the depth averaged flow in $\mathrm{x}$ and $\mathrm{y}$ directions respectively, $\mathrm{h}$ is total depth of water, $k_{x}, k_{y}$ is are sediment diffusion coefficient in $\mathrm{x}$ and $\mathrm{y}$ directions respectively, $\mathrm{E}$ is erosion rate of the suspended sediment and D is deposition rate of the suspended sediment.

$$
\begin{aligned}
& \text { (2) } E=C^{\prime} \omega \\
& \text { (3) } D=C \omega
\end{aligned}
$$

So, the term E-D is source-sink term (S) and represents exchange rate of water bed by computing erosion and deposition of sediments per unit width.

$$
S=E-D=\omega\left(C^{\prime}-C\right)
$$

Where: $\omega$ is settling velocity, $C^{\prime}, C$ are the depth averaged concentration of sediment under condition of equilibrium and the depth averaged actual concentration of sediment respectively.

\section{Bed load transport}

The governing equation of the bed load transport equation is developed by integrating the three-dimensional equation of sediment transport over the layer of bed load. Which that integrating produce sediment continuity in the layer of bed load and expressed by exner equation as:

$$
\begin{gathered}
\left(1-p^{\prime}\right) \frac{\partial z_{b}}{\partial t}+\frac{\partial\left(a c_{b}\right)}{\partial t}+\frac{\partial q_{b x}}{\partial x}+\frac{\partial q_{b y}}{\partial y}=D-E \\
q_{b x}=\alpha_{c b x} q_{b} \quad q_{b y}=\alpha_{c b y} q_{b} \\
q_{b}=a U_{b} C_{b}
\end{gathered}
$$

Where: $p^{\prime}$ is the porosity of the bed particle, $\mathrm{z}_{\mathrm{b}}$ is the bed layer depth, $q_{b x}, q_{b y}$ are components of bed load transport rate in $\mathrm{x}, \mathrm{y}$ directions respectively, $\alpha_{c b x}, \alpha_{c b y}$ are direction cosines of bed load transport rate in $\mathrm{x}$, $\mathrm{y}$ directions respectively, $U_{b}$ is the velocity of bed load transport, $C_{b}$ is the depth averaged concentration of sediment above bed layer zone, $a$ is the depth of bed layer.

\section{Change of bed elevation}

The change of bed elevation calculated with:

$$
\frac{\partial z_{b}}{\partial t}=\frac{\alpha \omega_{s}\left(C-C^{\prime}\right)}{\left(1-p^{\prime}\right)}+\frac{\left(q_{b}-q_{b}^{\prime}\right)}{\left(1-p^{\prime}\right) L_{t}}
$$

Where: $\mathrm{L}_{\mathrm{t}}=$ Non equilibrium adaptation coefficient is a length which concentration of sediment changes to equilibrium state from non-equilibrium state. 


\section{Numerical Method}

In this paper, the two-dimensional advectiondiffusion equation with source term (1), Was solved by the standard split operator (fractional step approach) Sobey (1983), Whereas we solved the hyperbolic part (advection) and parabolic part (diffusion) of the equation of sediment transport separately at each time step. The solution of this equation consists two different phases at each time step: 1 - Advection step: calculating by several methods of finite difference scheme.

2 - Diffusion step: calculating by semi implicit difference method.

The disadvantage of this method is separating these processes which occurring in discrete periods unlike what happens in nature which occur simultaneously. This leads to an additional splitting error that occurs regardless of how precisely the individual steps of equation are solved. So, the splitting error is not essential and is offset by the fact that numerical methods can be developed for divided sub problems that are more efficient than any undivided method. We can rewrite advection-diffusion equation of sediment transport as:

$$
\text { (9) } \frac{\partial C}{\partial t}+L_{c}(C)-L_{d}(C)=0
$$

Advection operator:

$$
L_{c}(C)=\frac{\partial U h C}{\partial x}+\frac{\partial V h C}{\partial y}
$$

Diffusion operator:

$L_{d}(C)=\frac{\partial}{\partial x}\left(k_{x} h \frac{\partial C}{\partial x}\right)+\frac{\partial}{\partial y}\left(k_{y} h \frac{\partial C}{\partial y}\right)+E-D$

Using the Taylor series expansion equation (9) can be written for the nth time step as:

$\frac{C^{n+1}-C^{n}}{\Delta t}+L_{c}\left(C^{n}\right)-L_{d}\left(C^{n}\right)=\frac{\Delta t}{2} \frac{\partial^{2} C^{n}}{\partial^{2} t}+\ldots=0(\Delta t)$

Introducing $C^{\prime}$ as auxiliary variable and then separate (12) to two equations as:

Advection step:

$$
\frac{C^{\prime}-C^{n}}{\Delta t}+L_{c}\left(C^{n}\right)=0
$$

Diffusion step:

$$
\frac{C^{\prime}-C^{n}}{\Delta t}-L_{d}\left(C^{n}\right)=0
$$

\subsection{Advection Step Solution}

Many researchers demonstrated several methods to solve the advection equation. A conservative form of advection of scalar concentration or density function $\mathrm{C}(\mathrm{x}, \mathrm{t})$ can be written, in general:

$$
C_{t}+\nabla \cdot(U C)=0
$$

For incompressible flow, advection equation in $2 \mathrm{D}$ is:

$$
C_{t}+(U C)_{x}+(V C)_{y}=0
$$

For compressible flow, advection equation in 2D is:

$$
C_{t}+U C_{x}+V C_{y}=0
$$

To obtain a first order method, we us the finite difference method and replacing $C_{t}$ by a forward in time approximation

$$
C_{t}=\frac{C_{\mathrm{i}, \mathrm{j}}^{n+1}-C_{\mathrm{i}, \mathrm{j}}^{n}}{\Delta t}
$$

And $C_{x}, C_{y}$ by forward approximation

$$
C_{x}=\frac{C_{\mathrm{i}+1, \mathrm{j}}^{n}-C_{\mathrm{i}, \mathrm{j}}^{n}}{\Delta x} \quad C_{y}=\frac{C_{\mathrm{i}, \mathrm{j}+1}^{n}-C_{\mathrm{i}, \mathrm{j}}^{n}}{\Delta y}
$$

So, we get upwind scheme

$$
C_{\mathrm{i}, \mathrm{j}}^{n+1}=C_{\mathrm{i}, \mathrm{j}}^{n}-U \frac{\Delta t}{\Delta x}\left(C_{\mathrm{i}+1, \mathrm{j}}^{n}-C_{\mathrm{i}, \mathrm{j}}^{n}\right)-V \frac{\Delta t}{\Delta y}\left(C_{\mathrm{i}, \mathrm{j}+1}^{n}-C_{\mathrm{i}, \mathrm{j}}^{n}\right)
$$

To obtain Lax-Friedrich method we replace $C_{\mathrm{i}, \mathrm{j}}^{n}$ by the average

$$
C_{\mathrm{i}, \mathrm{j}}^{n}=\frac{1}{4}\left(C_{\mathrm{i}+1, \mathrm{j}}^{n}+C_{\mathrm{i}-1, \mathrm{j}}^{n}+C_{\mathrm{i}, \mathrm{j}+1}^{n}-C_{\mathrm{i}, \mathrm{j}-1}^{n}\right)
$$




$$
\begin{gathered}
C_{\mathrm{i}, \mathrm{j}}^{n+1}=\frac{1}{4}\left(C_{\mathrm{i}+1, \mathrm{j}}^{n}+C_{\mathrm{i}-1, \mathrm{j}}^{n}+C_{\mathrm{i}, \mathrm{j}+1}^{n}-C_{\mathrm{i}, \mathrm{j}-1}^{n}\right)- \\
U \frac{\Delta t}{2 \Delta x}\left(C_{\mathrm{i}+1, \mathrm{j}}^{n}-C_{\mathrm{i}-1, \mathrm{j}}^{n}\right)-V \frac{\Delta t}{2 \Delta y}\left(C_{\mathrm{i}, \mathrm{j}+1}^{n}-C_{\mathrm{i}, \mathrm{j}-1}^{n}\right)
\end{gathered}
$$

To get second order accuracy with $\mathrm{x}$ and $\mathrm{y}$ we used Lax-Wendroff scheme as

$$
\begin{gathered}
C_{\mathrm{i}, \mathrm{j}}^{n+1}=C_{\mathrm{i}, \mathrm{j}}^{n}-U \frac{\Delta t}{2 \Delta x}\left(C_{\mathrm{i}+1, \mathrm{j}}^{n}-C_{\mathrm{i}-2, \mathrm{j}}^{n}\right) \\
-V \frac{\Delta t}{2 \Delta y}\left(C_{\mathrm{i}, \mathrm{j}+1}^{n}-C_{\mathrm{i}, \mathrm{j}-1}^{n}\right) \\
+U^{2} \frac{\Delta t^{2}}{2 \Delta x^{2}}\left(C_{\mathrm{i}+1, \mathrm{j}}^{n}-2 C_{\mathrm{i}, \mathrm{j}}^{n}+C_{\mathrm{i}-1, \mathrm{j}}^{n}\right) \\
+V^{2} \frac{\Delta t^{2}}{2 \Delta y^{2}}\left(C_{\mathrm{i}, \mathrm{j}+1}^{n}-2 C_{\mathrm{i}, \mathrm{j}}^{n}+C_{\mathrm{i}, \mathrm{j}-1}^{n}\right) \\
+V U \frac{\Delta t}{4 \Delta x \Delta y}\left(C_{i+1, j}^{n}+C_{i-1, j}^{n}+C_{i, j+1}^{n}-C_{i, j-1}^{n}\right)
\end{gathered}
$$

\subsection{Diffusion Step}

The second part in advection diffusion equation of sediment transport is a diffusion part. It's described by the parabolic equation as:

$$
\frac{\partial h C}{\partial t}=\frac{\partial}{\partial x}\left(k_{x} h \frac{\partial C}{\partial x}\right)+\frac{\partial}{\partial y}\left(k_{y} h \frac{\partial C}{\partial y}\right)+S
$$

We used semi implicit finite difference scheme to solve this equation. So, we rewrite equation (22) as

$$
\frac{\partial h C}{\partial t}=\frac{\partial}{\partial x} M_{x}+\frac{\partial}{\partial y} M_{y}
$$

Which

$$
M_{x}=k_{x} h \frac{\partial C}{\partial x} \quad M_{y}=k_{y} h \frac{\partial C}{\partial y}
$$

With forward finite difference for equation (23)

$$
\begin{array}{r}
\frac{C^{n+1}(i, j) h(i, j)-C^{n}(i, j) h(i, j)}{\Delta t}=\frac{M_{x}(i+1, j)-M_{x}(i, j)}{\Delta x}+ \\
\frac{M_{y}(i, j+1)-M_{y}(i, j)}{\Delta y}+E(i, j)-D(i, j)
\end{array}
$$

Using

$$
M_{x}=k_{x} h \frac{\partial C}{\partial x}=k_{x} h\left[\theta C_{x}{ }^{n+1}+(1-\theta) C_{x}{ }^{n}\right]
$$

$$
\begin{gathered}
M_{x}=k_{x}(i, j) h(i, j)\left[\begin{array}{c}
\theta \\
\left.\frac{C_{i, j}^{n+1}+C_{i-1, j}^{n+1}}{\Delta x}\right)+ \\
(1-\theta)\left(\frac{C_{i, j}^{n}+C_{i-1, j}^{n}}{\Delta x}\right)
\end{array}\right] \\
M_{y}=k_{y}(i, j) h(i, j)\left[\begin{array}{l}
\theta \\
\left.\frac{C_{i, j}^{n+1}+C_{i, j-1}^{n+1}}{\Delta y}\right)+ \\
(1-\theta)\left(\frac{C_{i, j}^{n}+C_{i, j-1}^{n}}{\Delta y}\right)
\end{array}\right]
\end{gathered}
$$

Using equation (26) and (27) in (25)

$$
\begin{gathered}
\frac{C^{n+1}(i, j) h(i, j)-C^{n}(i, j) h(i, j)}{\Delta t}= \\
\frac{1}{\Delta x}\left\{\begin{array}{c}
k_{x}(i+1, j) h(i+1, j)\left[\begin{array}{l}
\theta \\
(1-\theta)\left(\frac{C_{i+1, j}^{n+1}+C_{i, j}^{n+1}}{\Delta x}\right)+C_{i, j}^{n} \\
\Delta x
\end{array}\right)
\end{array}\right] \\
\left.-k_{x}(i, j) h(i, j)\left[\begin{array}{cc}
\theta & \left.\left(\frac{C_{i, j}^{n+1}+C_{i-1, j}^{n+1}}{\Delta x}\right)+\right] \\
(1-\theta)\left(\frac{C_{i, j}^{n}+C_{i-1, j}^{n}}{\Delta x}\right)
\end{array}\right]\right\} \\
+\frac{1}{\Delta y}\left\{\begin{array}{c}
k_{y}(i, j+1) h(i, j+1)\left[\begin{array}{l}
\theta \\
\left(\frac{C_{i, j+1}^{n+1}+C_{i, j}^{n+1}}{\Delta y}\right)+
\end{array}\right) \\
(1-\theta)\left(\frac{C_{i, j+1}^{n}+C_{i, j}^{n}}{\Delta y}\right)
\end{array}\right] \\
\left.-k_{y}(i, j) h(i, j)\left[\begin{array}{cc}
\theta \quad\left(\frac{C_{i, j}^{n+1}+C_{i, j-1}^{n+1}}{\Delta y}\right)+ \\
(1-\theta)\left(\frac{C_{i, j}^{n}+C_{i, j-1}^{n}}{\Delta y}\right)
\end{array}\right]\right\}
\end{gathered}
$$

We can rearrange equation (28) to separate unknown terms $C^{n+1}$ as:

$$
\begin{gathered}
P U^{+}(i, j) C^{n+1}(i+1, j)+P U^{-}(i, j) C^{n+1}(i-1, j) \\
+ \\
P V^{+}(i, j) C^{n+1}(i, j+1)+P V^{-}(i, j) C^{n+1}(i, j-1) \\
+ \\
C^{n+1}(i+1, j)=B(i, j)
\end{gathered}
$$

Where B $(i, j)$ is known term of $C^{n}(i, j)$ Equation (29) represents linear system equations, $\mathrm{Ax}=\mathrm{B}$ and it can be solved 
numerically by biconjugate gradient stabilized method (Bi-CGTAB) method. Which it combines ideas of both CGS and SOR. (BiCGStab) algorithm is a variation of Conjugate Gradient Squared (CGS). As CGS is based on squaring the residual polynomial, and in cases of irregular convergence, this may lead to substantial build-up of rounding errors, or possibly even overflow. BICGSTAB was developed to remedy this difficulty.

\section{Vertical Distribution of the Sediment}

It's important to predict the vertical distribution concentration of the suspended particles in the flume, so many researchers worked on this problem. Hunter Rouse (1937) developed one of the most important equation to predict concentration of the suspend load, he studied rate of downward and upward settlement under equilibrium and get the next equation:

$$
C \omega+D_{s}\left(\frac{d C}{d z}\right)=0
$$

Where $D_{s}$ is sediment diffusion coefficient and usually assumed is proportional to kinematic viscosity, so it can be represented by the parabolic equation:

$$
D_{s}=u_{*} \kappa\left(\frac{z-z^{2}}{h}\right)
$$

The equilibrium solution of equation (24) represented by Rose 1937 known as the suspended sediment distribution equation

$$
\frac{C}{C_{a}}=\left(\frac{h-z}{z} \frac{a}{h-a}\right)^{\frac{\omega}{u_{* \kappa}}}
$$

Where: $\mathrm{h}$ is total depth from the bed, $C_{a}$ is reference concentration at level a, $u_{*}$ is shear velocity, and $\kappa$ is karmen number and equal 0.41 . The concentration near the bed is equal to average concentration.

\section{Model simulation}

Consider the initial concentration at $\mathrm{t}=0$

Is $C(x, y, 0)=0.25+0.25 \cos (\pi r(x, y))$

And $r=\frac{\min \left(\sqrt{\left(x-x_{o}\right)^{2}+\left(y-y_{o}\right)^{2}}, r_{o}\right)}{r_{o}}$

The concentration is zero everywhere except for small cone with radius of $0.15 \mathrm{~m}$, centered at $x_{o}=0.25$ and $y_{o}=0.25 \mathrm{~m}$. The simulation of this concentration represents the advection of concentration with pure translation along diagonal of the mesh.
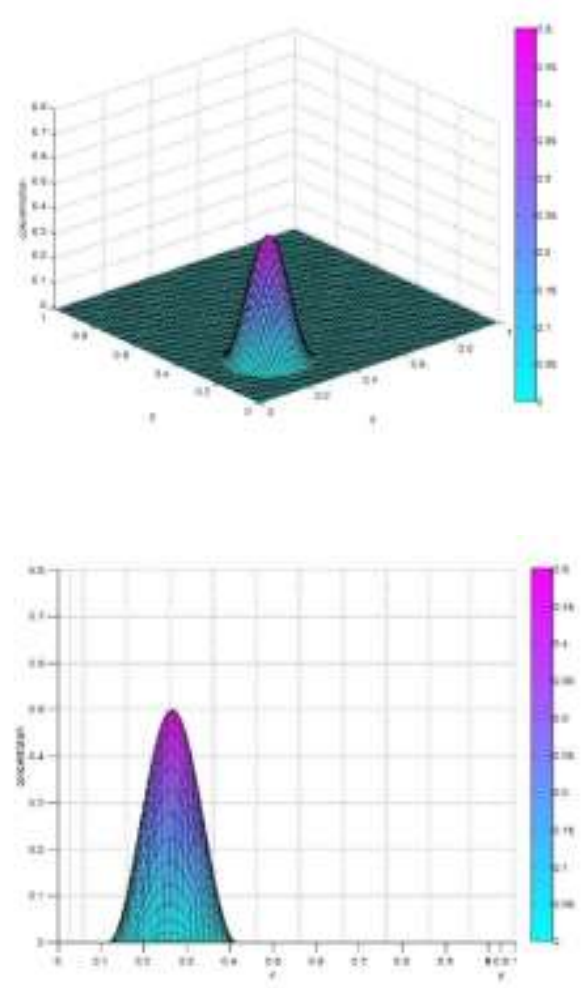

Fig.1 initial concentration

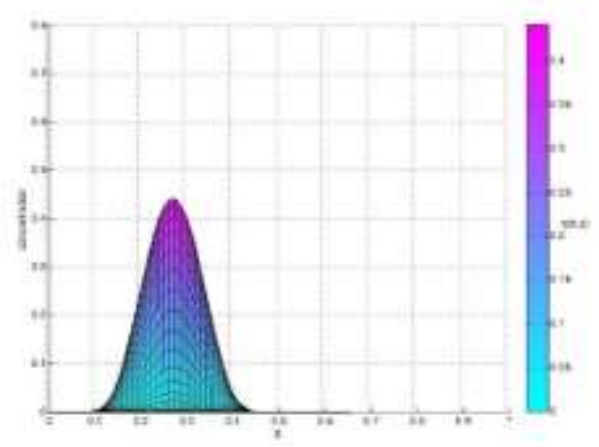

Fig. 2 concentration at $\mathrm{t}=0.3$ 


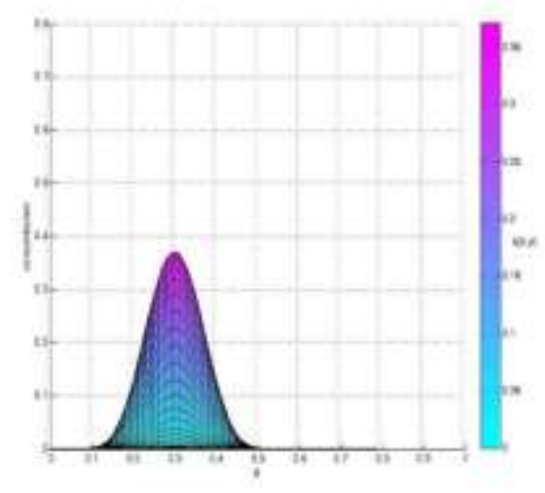

Fig. 3 concentration at $\mathrm{t}=0.5$

\section{Model approach}

The model calculates sediment transport in coastal area considering many variables and depends on data from hydrodynamic models. It used many approaches to calculate sediments either bedload or suspended load.

The model read the input data from hydrodynamical flow model and calculate suspended load or bedload of sediments transport. Then it applies advection step of sediment transport and adding source sink term which is calculated based on approaches of sediments, after that running diffusion step and calculate change in the bed elevation and concentration of sediment at each point. Figure (4)

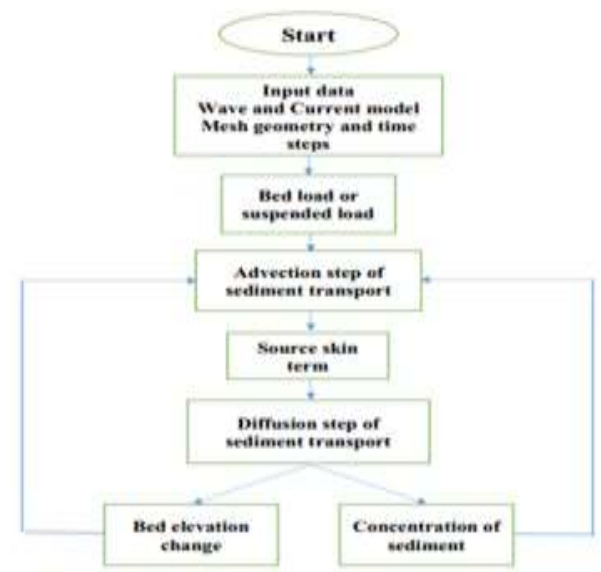

Fig.4 Flowchart of model

\section{Case Study}

We used the model to simulates sediment transport at the shoreline of New Mansoura city. Which that city is constructed recently, and it's important to predict the change of shoreline and bathymetric of this area after a period of time. The study area is located between (342547 E, $3489916 \mathrm{~N})$ and (344281 $\mathrm{E}, 3489014 \mathrm{~N}$ ), and it's about $1900 \mathrm{~m}$ in onshore direction and $1900 \mathrm{~m}$ in cross shore direction. The maximum water depth was 6.5 $\mathrm{m}$, and the water level at $\mathrm{z}=0$. The sediment density is $2650 \mathrm{~kg} / \mathrm{m} 3$, the density of water is $1025 \mathrm{~kg} / \mathrm{m} 3$, and the mean sediment diameter is $0.3 \mathrm{~mm}$.

\subsection{Hydrodynamic data}

Wind speed and direction time series are recorded at a height of $10 \mathrm{~m}$ of sea level in the study area over a period of a year with an interval of 1 day. Also, the wave high recorded over a period of a year with an interval of 1 day. For the hydrodynamic part, we used the XBeach model to simulate the hydrodynamic processes. XBeach is an open-source numerical model which is originally developed to simulate hydrodynamic processes. Then we used the output of the hydrodynamic model to simulate morphodynamic changes.

\subsection{Model setup}

The study area is divided into a grid with $\Delta \mathrm{x}$ $=\Delta \mathrm{y}=30 \mathrm{~m}$ in $\mathrm{x}$ and $\mathrm{y}$ directions, in which the $\mathrm{x}$-axis is perpendicular to the shoreline and the $y$-axis is parallel to the shoreline, Fig (5). The simulation time was a year.

\subsection{Results}

We used the model to simulate this area and found the sediment transport in two directions suspended and bed load transport. The model calculated the sediment concentration of suspended and bed load. Depth averaged suspended and bed equilibrium concentration and sediment concentration integrated from 
advection-diffusion equation are calculated. Finally, the change of bed elevation occurs as a result of all these variables. We found the changes occur in the zone near to the shoreline, so we will focus on the last $300 \mathrm{~m}$ from the shoreline. We divided the simulation processes over the year into 36 runs, every run simulates about ten days. Some runs represent the days that have high wind speed and a significant wave high, and others simulate the remaining days. We get the hydrodynamics data like wind speed, wave high, direction, and the period from (www. surf-forecast. com). We simulated the runs separately and used the output of every run as input to the next run. Finally, we have compiled all output and found the final data after one year of simulation. We will discuss the cumulative results after a year and represent the changes that occurred.

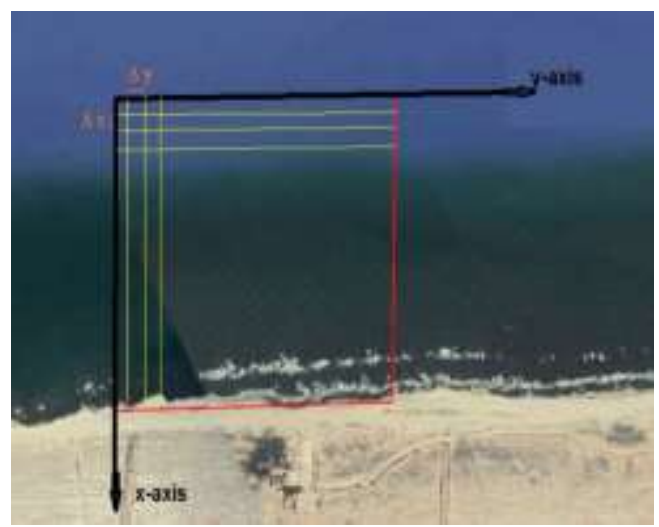

Fig.5 Axis and grid of the study area

The model simulates bed and suspended sediment transport in two directions, crossshore (x-axis) and onshore (y-axis). The distribution of bed sediment transport shown in figure (8). The distribution of suspended sediment transport in two directions shown in figure (9). Figure (10) show the sediment transport integrated over the bed and suspended load (total sediment transport).

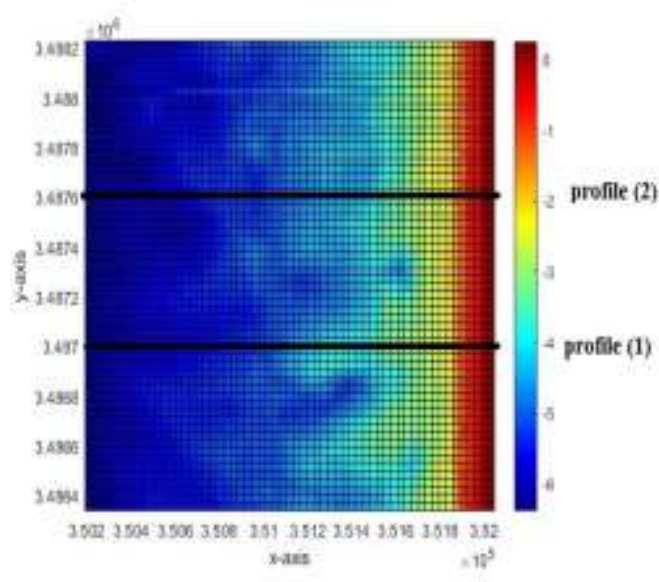

Fig.6 Axis and grids of study area and location profiles

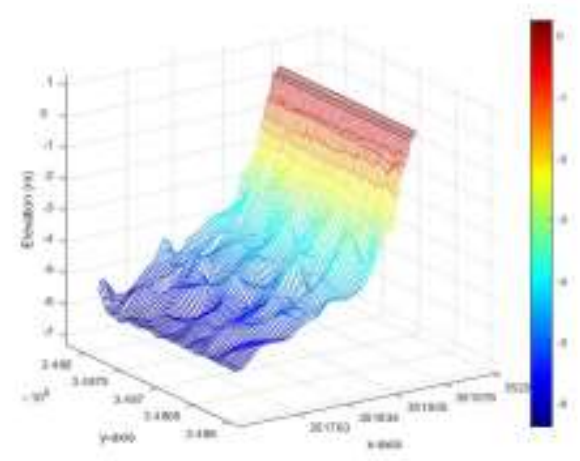

Fig. 7 Initial bathymetry 


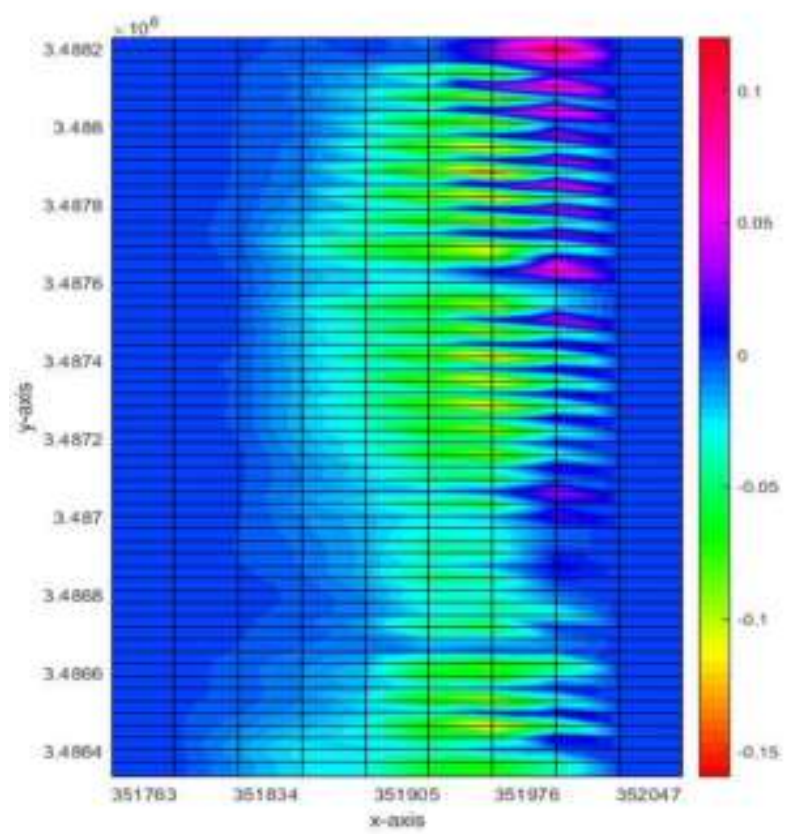

Fig. 8 Distribution of bed sediment transport $\mathrm{m} / \mathrm{s}^{2}$

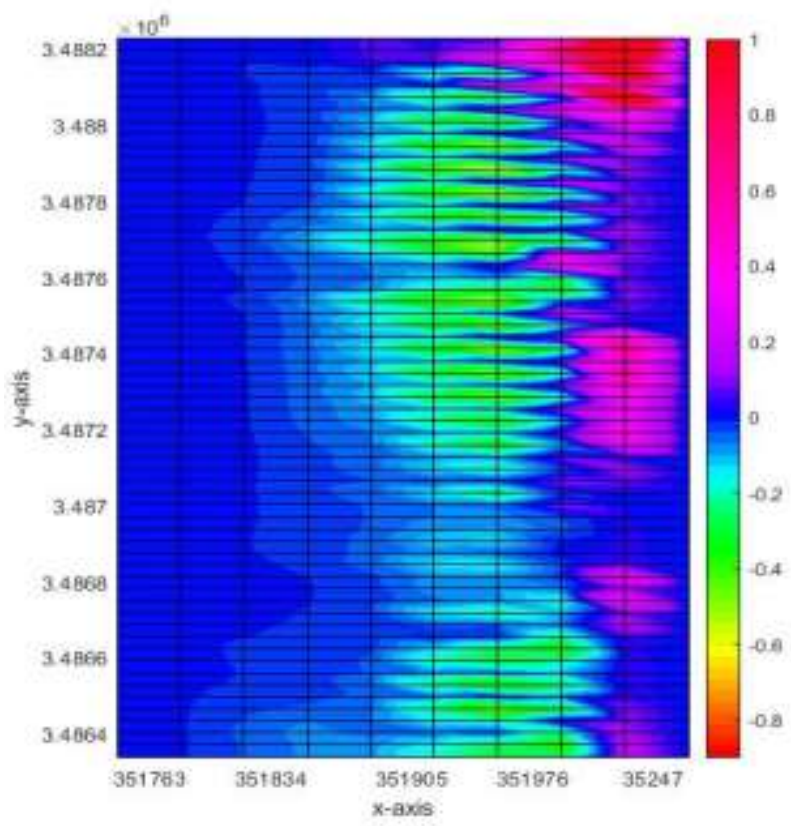

Fig. 9 Distribution of suspended sediment transport $\mathrm{m} / \mathrm{s}^{2}$ 


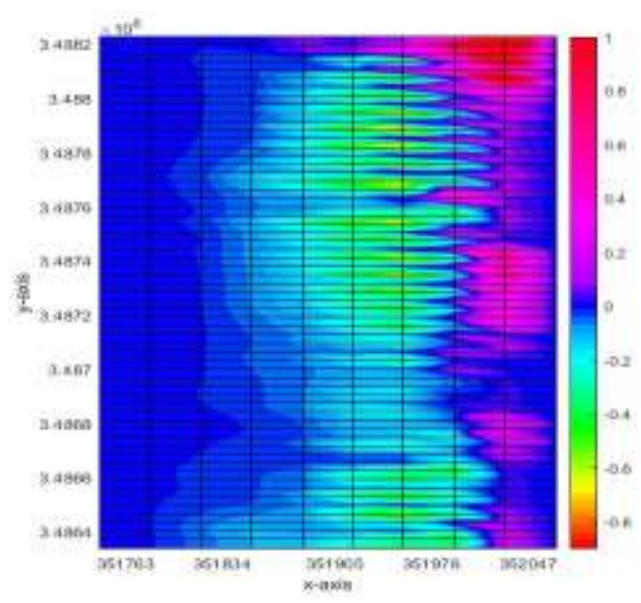

Fig. 10 Distribution of sediment transport integrated over bed and suspended load $\mathrm{m} / \mathrm{s}^{2}$
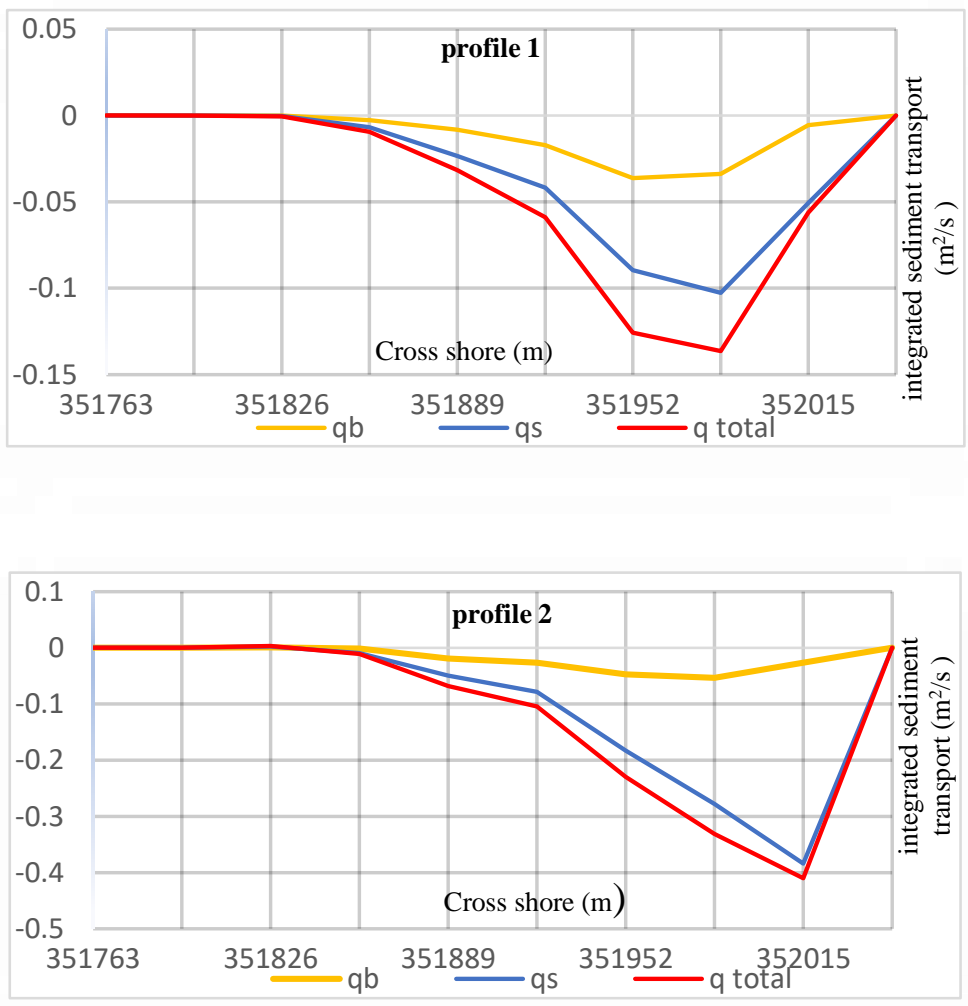

Fig. 11 Sediment transport integrated over bed and suspended load in profile (1) and profile (2) $\mathrm{m} / \mathrm{s}^{2}$ 


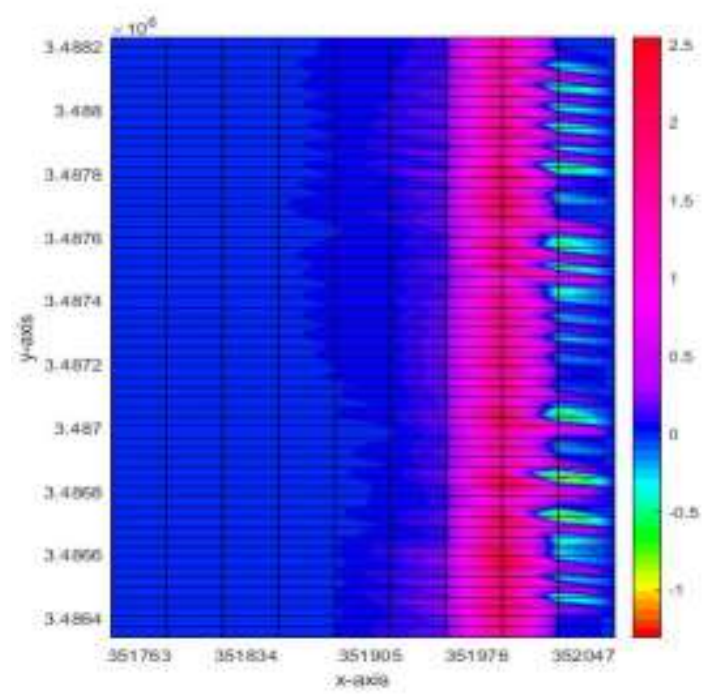

Fig. 12 Suspended concentration gradient $\mathrm{kg} / \mathrm{m}^{3} / \mathrm{m}$

Sediment transport of suspended and bed load caused to changing in bed elevation by erosion and deposition processes with the rate of changing in bed level as shown in next figures.

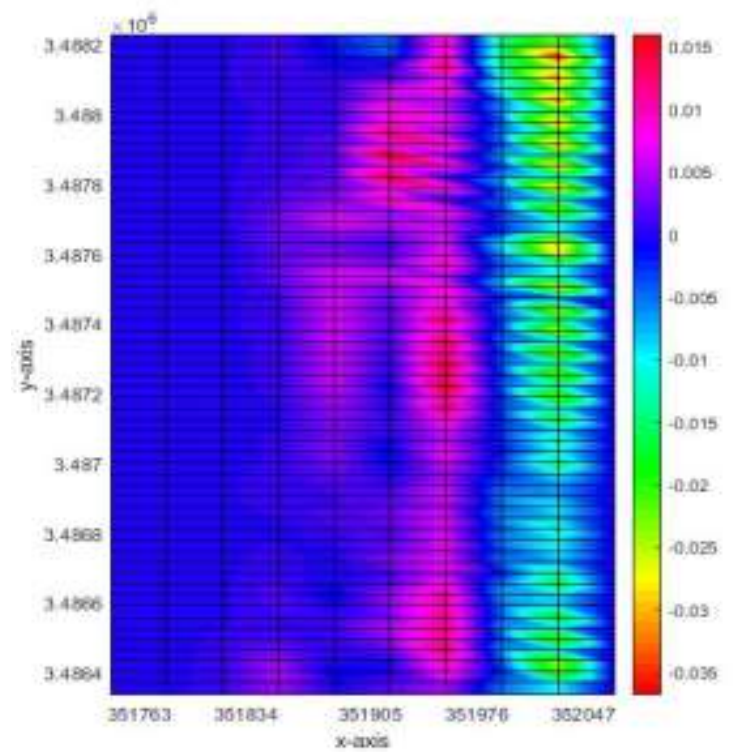

Fig. 13 Rate of change bed level $\mathrm{m} / \mathrm{s}$ 
The deposition and erosion processes that occur to the bed as a result of sediment that the main reason for changing the shape and elevation of the bed. The next figures show these processes for the chosen sections.

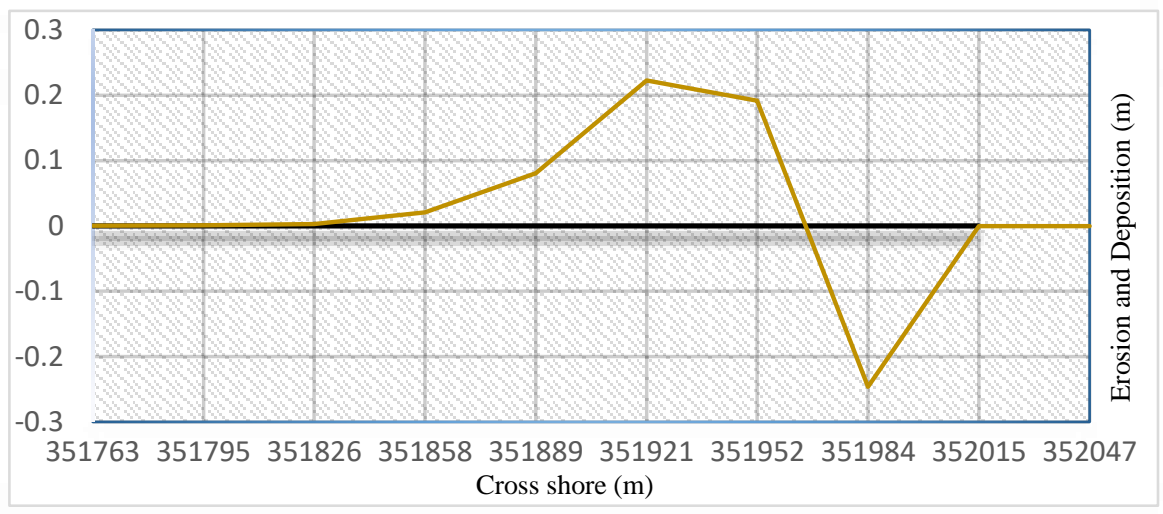

Fig. 14 Erosion and deposition in bed layer of profile (1)

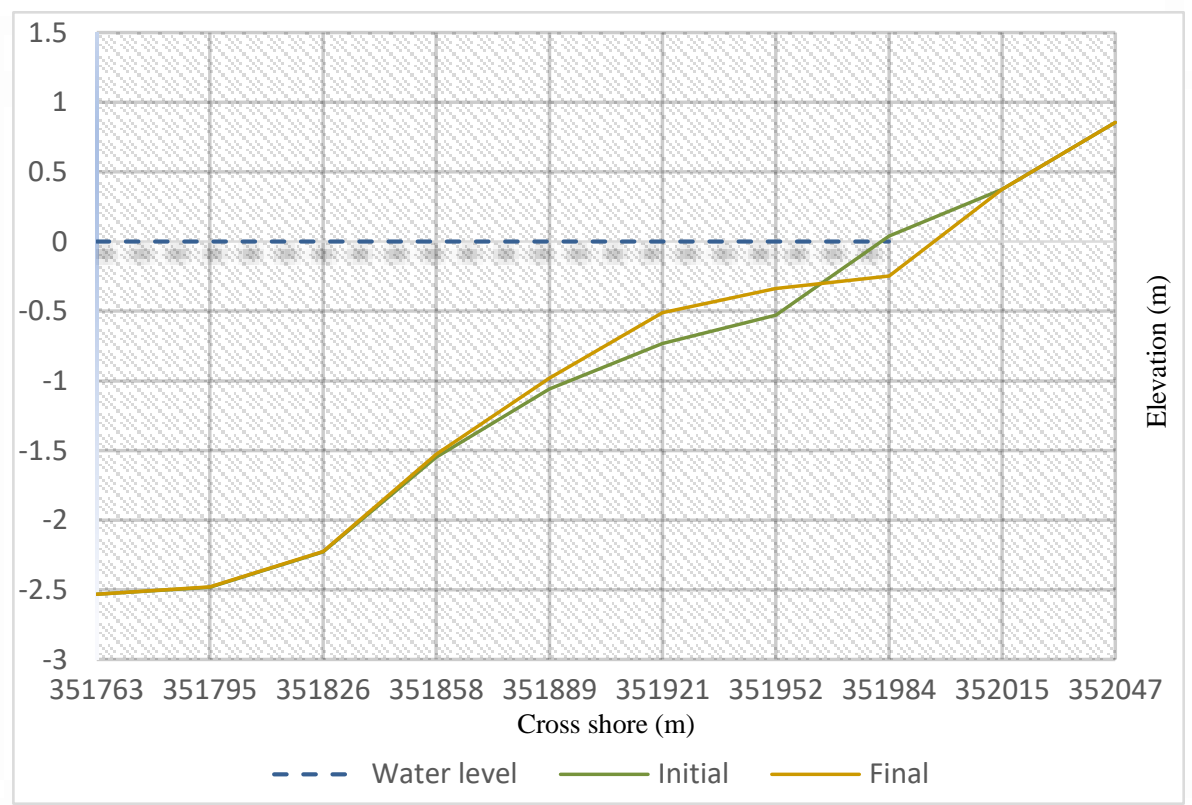

Fig. 15 Change of bed elevation profile (1) 


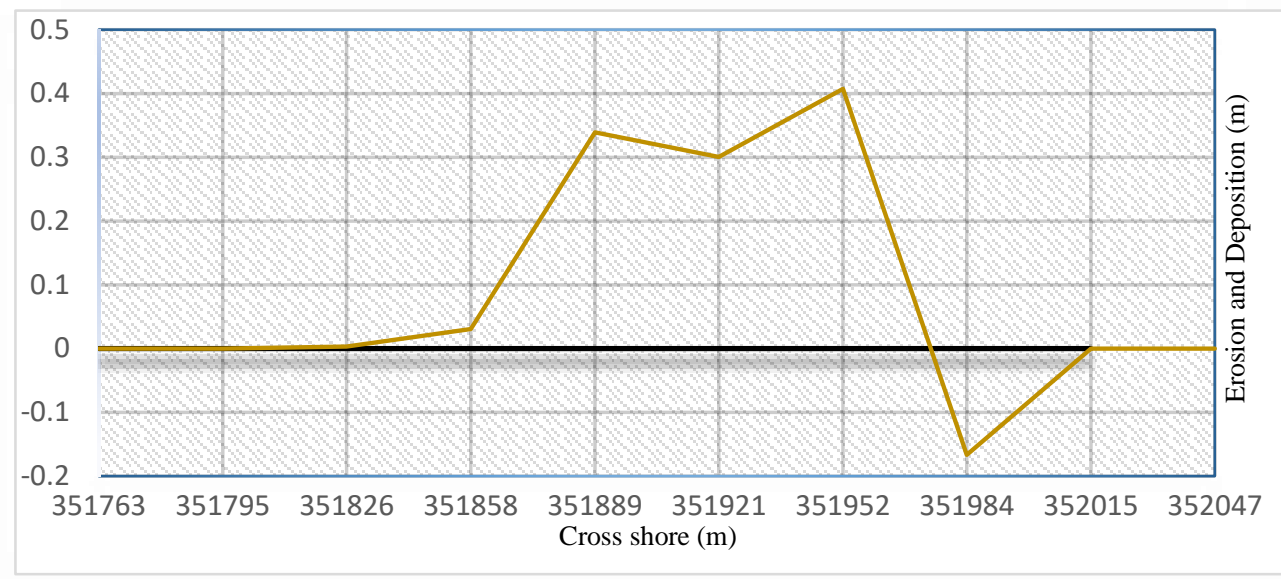

Fig. 16 Erosion and deposition in bed layer of profile (2)

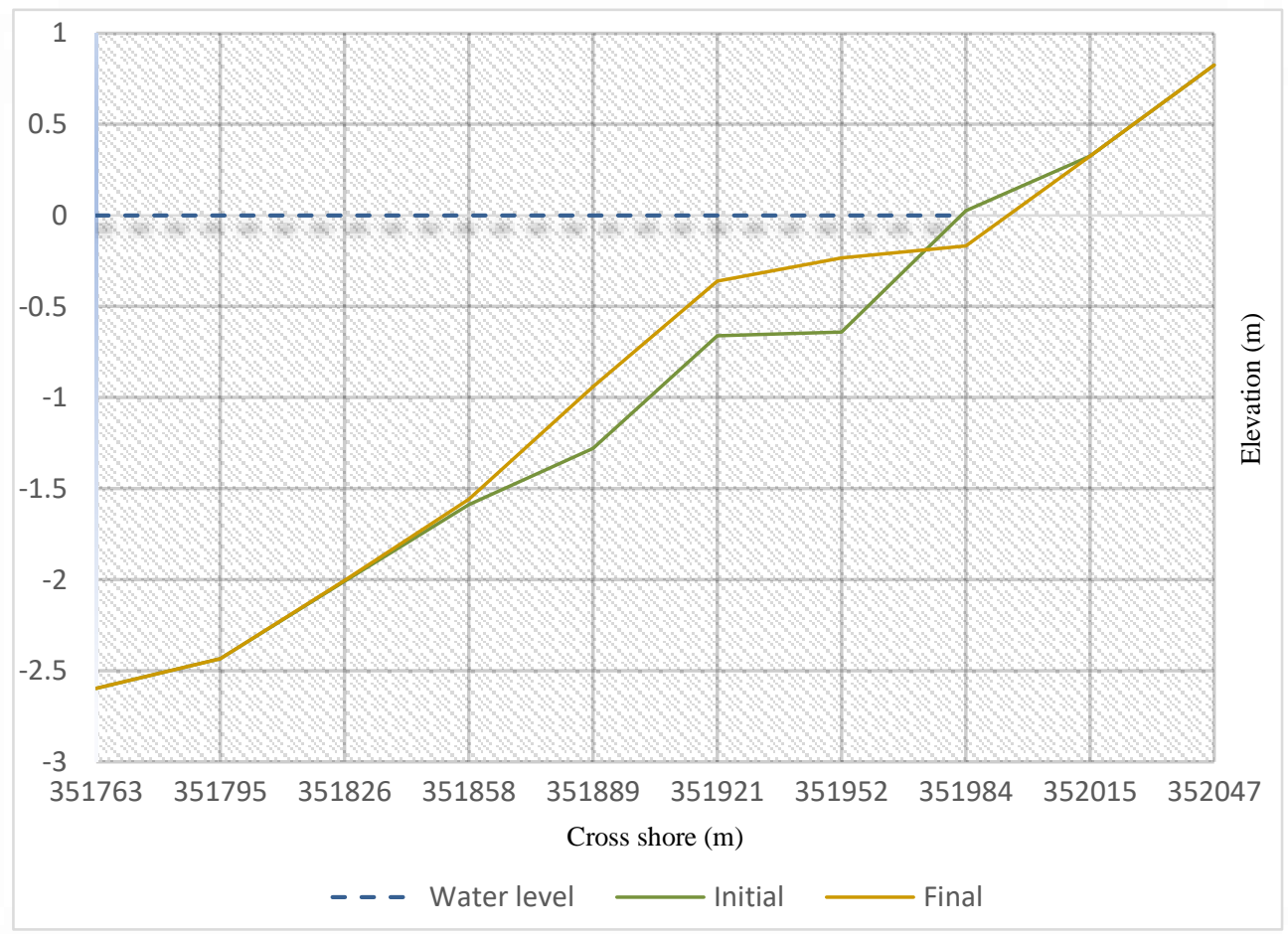

Fig. 17 Change of bed elevation profile (2) 


\section{Conclusion}

Through this paper, we obtained the concentration of suspended sediment transport from a depth-averaged advection-diffusion equation with source term to predict suspended, bed load transport, and bed elevation change. The source term represents the difference between the deposition of the bed surface and the entrainment of the suspended sediment. Fractional step method used to solve this equation by separating it into the advection step and diffusion step. Each step solved separately. The advection step solved by the finite difference method. For the diffusion step, we used semi implicit finite difference method which can be converted to a complete implicit scheme. It represents a linear system of equations and that system can be generated from partial differential equations and numerically by the biconjugate gradient stabilized method (Bi-CGTAB) method. This paper provides results that allow us to explore the evolution of the coast and the morphodynamics along the shores. We can simulate bed load or suspended load transport. Sediment transport depends on hydrodynamics variables like wind speed, wave high, direction period, and diameter of sediment. If the values of these variables changed, such as the wave height, the greater number of sediments transported, and caused changes and complications in the shape of the bed and its elevation, as is evident in turbulent climates such as winter. In our case study, we saw the amount of suspended sediment transport higher than the bed sediment transport. That's leads to a high suspended concentration. Most changes occur in the zone located near the shoreline or any structure's zones. The large amount of sediment transported in an across-shore direction. Bed shear stress increases shoreward, incrementally in the shoaling zone.
Acker P., White W. R, "Sediment transport: A new approach and analysis", Journal of hydraulics division, ASCE, 99(HY11), pp. 2041-2060, (1973).

Atilla B., Magnus L., Herman C. M. and Nicholas C. K., "Cross-shore distribution of longshore sediment transport: comparison between predictive formulas and field measurements", An International Journal for Coastal, Harbour and Offshore Engineers, 44, pp. 79-99, (2001).

Bagnold R. A., "An approach to the sediment transport problem from general physics", Geological survey prof, Washington, pp. 422I, (1966).

Bermudez A. and Vazquez M. E., "Upwind methods for hyperbolicn conservation laws with source terms", Computers and Fluids 23, pp. 1049-1071, (1994).

Bijker E.W., "Long-shore transport computations", Journal of the Waterways, Harbors and Coastal Engineering, 97(4), pp. 687- 703, (1971).

Colella P., "Multidimensional upwind methods for hyperbolic conservation laws", Journal of Computational Physics, 87, pp. 171-200, (1990).

Cunge J.A. and Perdreau N., "Mobile bed fluvial mathematical models", LaHouille Blanche, 7, pp. 561-580, (1973).

De Vriend H.J., “2DH Mathematical Modelling of Morphological Evolutions in Shallow Water", Coastal Engineering 11, pp. $1-27,(1988)$

De Vries M. and Vreugdenhil C. B., "Computations of non-steady ved load transport by a preudo viscosity method", Proc. IAHR 12th congress, La Houille, 3 , (1967).

\section{References}


DHI Inc., 301 South State Street, Newtown, PA, 18940, (2003), USA.

http://www.dhisoftware.com.

Einstein H. A., "The bed load function for sediment transportation in open channel flows", U.S. department of agriculture, Soil conservation service, Technical bulletin No. 1026, (1950).

Garde R. J., "Aggradation upstream of a reservoir", Research journal, University of Roorkee, 8, pp. 65-72, (1965), roorkee.

Garde R. J. and Ranga Raju K. G., "Mechanics of sediment transportation and alluvial stream problems", Wiley Eastern Limited, (1978), India.

Gesseler J., “Aggradation and degradation”, River mechanics, 1, Fort Collins, (1971), Colorado.

Habibi M., "Sediment transport estimation methods in river systems", Ph.D. thesis, Department of Civil and Mining Engineering, University of Wollongong, (1994), Australia.

Habibi M. and Sivakumar. M., "New Formulation for Estimation of Bed Load Transport", Proc. International Conference on Hydraulics in Civil Engineering, University of Queensland, Brisbane, pp. 81-86, (1994), Australia.

Hayter E. j., Bergs M. A., Gu R.,McCutcheon S., Simth S. J. and Whiteley H. J., "HSCTM2D, A finite element model for depth averaged hydrodynamics", sediment and contaminant transport.

Hudson J., "Numerical Techniques for Morphodynamic Modelling", Ph.D. thesis, Department of Mathematics, University of Reading, (2001), Whiteknights.

Ishraga S.O., Bare S., Akode O., and Suryadi F.X., "Simulation of Fine Sediment Transport in Irrigation Canals of the Gezira Scheme with the Numerical Model FSEDT", Journal of Irrigation and Drainage Engineering, 142 (11), (2016).
Jarmillo W. F. Torres, “Aggradation and degradation of alluvial-channel beds", Ph.D. Thesis, University of Iowa, (1983).

Junke G., Pierre Y. J., "Efficient Algorithm for Computing Einstein Integrals", Journal of hydraulic engineering, 130(12), pp. 11981201, (2004).

Karim M. F., Kennedy J. F., "IALLUVIAL: a computer based a flow and sediment routing for alluvial streams and its application to the Missouri River", Hydraulic research, report (250), University of Iowa, (1982).

LeVeque J.R. and Yee. C.H., "A Study of Numerical Methods for Hyperbolic Conservation Laws with Stiff Source Terms", Journal of Computational Physics 86, pp.187 -210 , (1990).

LeVeque J.R., "Numerical Methods for Conservation Laws", Birkhäuser Verlag, ISBN 3-7643-2723-5, (1992).

Leveque J.R., "High resolution conservative algorithm for advection in incompressible flow', Journal of Numerical Analysis, 33(2), pp. 627-665, (1996).

LeVeque. J.R.,” Balancing Source Terms and Flux Gradients in High-Resolution Godunov Methods: The Quasi-Steady Wave Propagation Algorithm", Journal of Computational Physics, 146, (1998),

Mahmood K., "Mathematical modeling of Morphological transients in sand bed channels", Proc. of IAHR 16th congress, 2, (1957).

Meyer-Peter E. and Muller R., "Formulas for Bed Load Transport" Proc. third Meeting of LAHR, Stockholm. pp. 39-64, (1948).

Nikmanesh M.R. and Talebbeydokhti N. "Numerical simulation for predicting concentration profiles of cohesive sediments in surf zone" Scientia Iranica, 20(3), pp.454465, (2013). 
Rubey, W. W., "Settling velocities of gravel, sand and silt particles", American journal of science, 25, pp. 325-338, (1933).

Saber M. Elsayed, "Breaching of Coastal Barriers under Extreme Storm Surges and Implications for Groundwater Contamination", Ph.D. thesis, Faculty of Architecture, Civil Engineering and Environmental Sciences of the Technical University Carolo-Wilhelmina, (2017), Braunschweig.

Shuangcai L., Christopher J. D., ” Fully coupled approach to modeling shallow water flow, sediment transport, and bed evolution in rivers", Water Resource Research, 47,(2011).

Singh, V., "Two dimensional sediment transport model using parallel computers", Thesis with Degree of Master of Science in the Graduate Faculty in the Department of Civil and Environmental Engineering, Louisiana State University,(2005), USA.

Sobey, R.J., "Fraction step algorithm for estuarine mass transport', International Journal of Numerical Methods in Fluids, 3, pp. 749-772, (1983).

Struiksma N., Oleson K. W., Flokstra C. and De vriend H. J., "Bed deformation in curved alluvial channels", Journal of Hydraulic Research, 23(1), (1985).

Swamee P.K., "Analytical and experimental investigation of stream bed variation upstream of a dam", Ph.D. Thesis, University of Roorkee, (1974), Roorkee.

Syeda. W.R.,'Numerical modelling of sediment transport in the arctic", Thesis with Degree of Master of costal and marine engineering and management (COMEM), Department of Civil and Transport Engineering. Norwegian University of Science and Technology, (2015).

Thomas, W.A. and Prashum, A.L., "Mathematical Model of scour and deposition". J. Hydr. Div., 110(11), pp. 16131641, (1979).

Thomas, W. A. and McAnally, W. H., Jr., "User's Manual for the Generalized Computer Program Systems for Open Channel Flow and Sedimentation: TABS-2 system", US Army Corps of Engineers, Waterways Experiment Station, Hydraulics Laboratory, (1990), Vicksburg, MS.

Van der Vorst H. A., "Bi-CGSTAB: A fast and smoothly converging variant of Bi-CG for the solution of nonsymmetric linear systems". SIAM J. Sci. Stat. Comp., 13(2), pp. 631:644, (1992).

Van Rijn., "Sediment transport part I: bed load transport", Journal of hydraulic engineering, 110 (HY10), pp.1431-1456, (1984).

Van Rijn., "Mathematical modeling of suspended sediment in nonuniform flows", Journal of hydraulic engineering, 112, pp. 433-455, (1986).

Van Rijn., "Mathematical modeling of morphological processes in the case of suspended sediment transport", Delft Hydraulics. Communication no. 382, (1987).

Van Rijn., "Handbook: sediment transport by currents and waves", Rep. H461, Delft Hydraulics, (1989), Delft, The Netherlands.

Wu W., CCHE2D-2.1, Sediment Transport model, Technical report no. NCCHE-TR2001-3, National Center for Computational Hydroscience and Engineering, the University of Mississippi, (2001). 
معدلات نقل الرواسب في منطقة المنشآت المائية البعيدة و المتاخمة للشاطئ

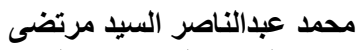

$$
\begin{aligned}
& \text { قسم الرياضيات و الفيزيقا الهندسية ــ الميكانيكا الهندسية } \\
& \text { كلية الهندسة - جامعة الفيوم } \\
& \text { أ.د.// محمد عيسى سيد أحمد } \\
& \text { استاذ الميكانيكا الهندسية - قسم الرياضيات و الفيزيقا الهندسية } \\
& \text { كلية الهندسة - جامعة الفيوم } \\
& \text { د./ محمد أحمد مراد }
\end{aligned}
$$

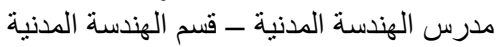

$$
\begin{aligned}
& \text { كلية الهندسة - جامعة الفيوم } \\
& \text { د./أحمد محمد عبدالتواب القيسي } \\
& \text { مدرس الميكانيكا الهندسية ـ قسم الرياضيات و ألفيزيقا الهندسية } \\
& \text { كلية الهندسة - جامعة الفيوم الرياضيات }
\end{aligned}
$$

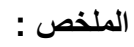

من المعروف جيدا ان عملية تدفق المياه في منطقة المياه الضحلة وبالقرب من المنشات والهياكل البحرية الى أسفل المنحدر وما

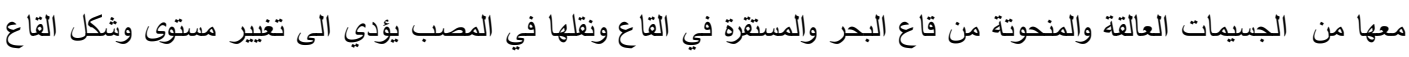

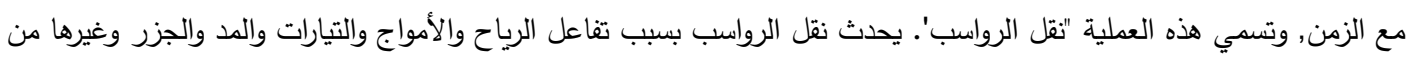
الظواهر في المنطقة الساحلية. والمصادر الرئيسية لإنتاج الرواسب هي التجويه من الصخور والتعرية بتدفق المياه فوق أسطح التربة.

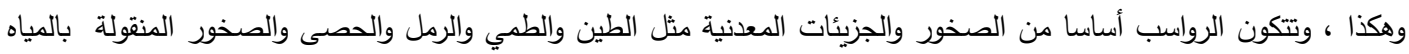
المتدفقة. وبناء علي ذلك ، يمكن تصنيف نقل الرواسب علي انه نقلٍ للرواسب بشكل موازٍ للشاطئ وعمودي على الثاطئ. وهنالك

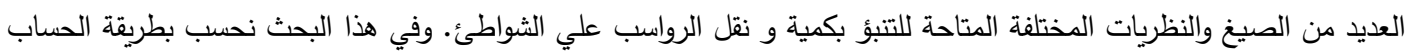

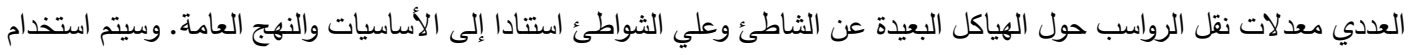

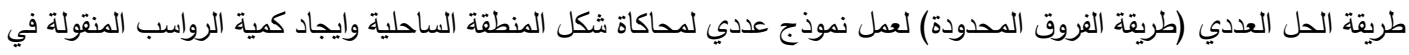
الاتجاهات الثاطئية والعامودية للشاطئ ، والتغيرات في مستوي القاع عند كل نقطه عقديه في الثبكة كما انه يبدا في حساب حقل

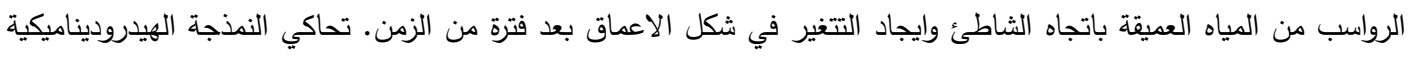

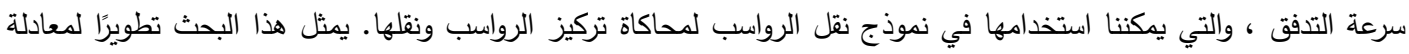

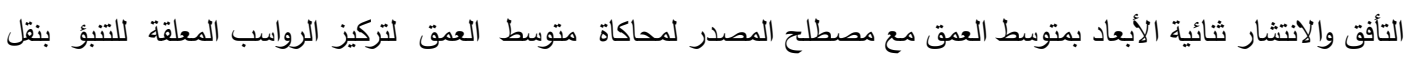

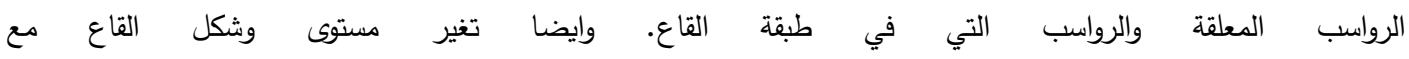
الزمن. 